Letrônica, Porto Alegre, v. 7, n. 1, p. 351-365, jan./jun., 2014

\title{
RAKUSHISHA: HETEROTOPIAS, NÃO-LUGARES E SILÊNCIO
}

\author{
RAKUSHISHA: HETEROTOPIAS, NON-PLACES AND SILENCE
}

\author{
Ana Amélia Gonçalves da Costa*
}

\begin{abstract}
Resumo: "Essa história começa ao rés do chão, com passos". Assim Michel de Certeau inicia o capítulo "A fala dos passos perdidos", contido no livro A Invenção do Cotidiano. No citado capítulo, de Certeau aproxima o ato de caminhar ao processo enunciativo. Diz ele: "Existe uma retórica da caminhada. A arte de moldar frases tem como equivalente uma arte de moldar percursos" (DE CERTEAU, 2000, 179). Entretanto, ainda segundo de Certeau, uma figuração mais onírica da prática do espaço nos leva a definir que "caminhar é ter falta de lugar. É o processo indefinido de estar ausente e à procura de um próprio" (DE CERTEAU, 2000, 183). "Para andar, basta colocar um pé depois do outro. Um pé depois do outro" (LISBOA, 2007, p. 9). Com esta frase, a escritora carioca Adriana Lisboa inicia seu romance Rakushisha. Quem caminha, escreve e nasce é Celina, a protagonista de Lisboa. Três açõ es sobrepostas, tal como a estrutura narrativa do romance em questão. Do Rio de Janeiro ao Japão, a personagem Celina transita pelos não-lugares da supermodernidade, termos conceituados por Marc Augé. Para ser anônima, entretanto, e ganhar o direito de tornar-se similar, Celina precisa recuperar sua identidade, precisa "assinar o contrato" com os outros usuários do não-lugar. E é assim que o Diário de Saga, escrito pelo poeta japonês Matsuo Bashô no século XVII, fará com que a protagonista de Rakushisha se olhe no espelho e se reconheça 'um'. Espelho que, segundo Michel Foucault, é a "experiência mista, mediana" entre a utopia (modelo ideal) e a heterotopia (modelo real).
\end{abstract}

Palavras-chave: Identidade; Anonimato; Não-lugar; Heterotopia.

\begin{abstract}
This story begins at ground level, by footsteps." These words introduce "The speech of lost steps", a chapter of Michel de Certeau's The Practice of Everyday Life. Certeau understands the act of walking as an enunciative process. He says: "There is a rhetoric of walking. The art of shaping phrases is equivalent to the art of shaping pathways "(DE CERTEAU, 2000, 179). However, according to him, we can define the practice of space in such an onirical conception like "Walking is lacking of space. It is the indefinite process of being absent and in search of your own "(DE CERTEAU, 2000, 183). "If you should walk, just put one foot after the other. One foot after the other "(LISBOA, 2007, p. 9). With this sentence, Brazilian writer Adriana Lisboa begins her novel Rakushisha. Celina, her main character, is a woman that walks and writes. The narrative structure of this novel is developed in three overlapping actions: from Rio de Janeiro to Japan, Celina moves in a way that we could think at Marc Augé's concept of non-places of supermodernity; however, to remain anonymous and be able to become similar, Celina needs to recover her identity by "signing a contract" with other users of a non-place; for doing so, the lecture of the Daily Saga, written by the seventeenth century Japanese poet Matsuo Basho, will help her to look at the mirror and recognize herself as 'one'. A mirror as the "mixed and median experience", according to Michel Foucault, between utopia (ideal model) and heterotopia (real model).
\end{abstract}

Keywords: Identity; Anonymity; Non-place; Heterotopia.

\footnotetext{
${ }^{*}$ Mestre em Teoria da Literatura e Literatura Comparada (UERJ) e Doutoranda em Literatura Comparada
} (UERJ), com Bolsa de estudos oferecida pela Capes. 
No século $\mathrm{XX}$, a questão do espaço passa a figurar em teorias e críticas de pensadores, complementando e renovando o olhar que, até então, concentrava-se na problemática estabelecida pela noção de tempo. Em uma conferência realizada em 1967, intitulada "Outros Espaços", Michel Foucault anuncia esse "entrecruzamento fatal do tempo com o espaço": "A época atual seria talvez de preferência a época do espaço. Estamos na época do simultâneo, estamos na época da justaposição, do próximo e do longínquo, do lado a lado e do disperso" (FOUCAULT, 2006, p. 411). Na mesma conferência, o filósofo francês forja o conceito de heterotopia (hetero: outro / topos: lugar), definido como uma localização física da utopia.

Compreendida como o lugar em si mesmo em relação a outros lugares, a heterotopia, de acordo com Foucault, pode ser qualificada a partir de alguns princípios gerais. Inicialmente, a heterotopia está presente em todas as culturas, por ser "uma constante de qualquer grupo humano" (2006, p. 411). A função de uma mesma heterotopia, entretanto, pode variar através do tempo e "segundo a sincronia da cultura na qual ela se encontra" (2006, p. 411). Em seguida, o filósofo explicita que "a heterotopia tem o poder de justapor em um só lugar real vários espaços, vários posicionamentos que são em si próprios incompatíveis" (2006, p. 411). É o caso do teatro, do cinema ou do jardim oriental, por exemplo. No decorrer da conferência, Foucault analisa que no interior da conceituação de heterotopia pode existir o que ele chamou de heterocronia, ou seja "uma espécie de ruptura absoluta com seu tempo tradicional" (2006, p. 411), cujos exemplos concretos seriam os museus e as bibliotecas. O quinto princípio apontado pelo filósofo é o que designa que "as heterotopias supõem sempre um sistema de abertura e fechamento que, simultaneamente, as isola e as torna penetráveis" (FOUCAULT, 2006, p. 411).

Entre as várias heterotopias citadas por Michel Foucault, três merecem atenção especial por suas exemplaridades: o espelho, o cemitério e o barco. 0 espelho seria a "experiência mista, mediana" entre a utopia (modelo ideal) e a heterotopia (modelo real). O cemitério, lugar que "sofreu mutações importantes" através dos séculos, explicita a variação funcional da heterotopia através do tempo, permitindo, assim, destacar a preocupação do filósofo em discorrer sobre a noção histórica do espaço, conforme já mencionado: 
É preciso, entretanto, observar que o espaço que hoje aparece no horizonte de nossas preocupações, de nossa teoria, de nossos sistemas não é uma inovação: o próprio espaço na experiência ocidental tem uma história, e não é possível desconhecer este entrecruzamento fatal do tempo com o espaço. (FOUCAULT, 2006, 411-412).

Já o barco, exemplo que encerra a conferência supramencionada, é tido por Foucault como a heterotopia por excelência, se soubermos ir além de sua função desenvolvimentista e explorarmos a "reserva de imaginação" oferecida à humanidade pelo meio de transporte: "Nas civilizações sem barcos os sonhos se esgotam, a espionagem ali substitui a aventura e a polícia, os corsários" (FOUCAULT, 2006, p. 411).

\section{A heterotopia da "moradia irreal"}

Ao articular heterotopia e imaginação, o barco foucaultiano nos conduz a águas ficcionais, que, também espelhos, criam espaços e refletem suas imagens. A metáfora especular também permeia a construção narrativa de Rakushisha, romance que a escritora carioca Adriana Lisboa publicou em 2007. Traspassada por fragmentos do diário e por haicais de autoria do poeta japonês Matsuo Bashô a obra de Lisboa, da qual faremos uma leitura especificamente espacial, relata a viagem de dois desconhecidos ao Japão.

Em 1691, o poeta viajante Bashô se hospeda na Cabana dos Caquis Caídos, Rakushisha, nos arredores de Kyoto, para escrever o Diário de Saga. É a tradução em língua portuguesa deste diário que o personagem Haruki vai ilustrar, trabalho que o conduz, através de uma bolsa, ao Japão de seus ancestrais. A viagem ao país de Bashô é realizada em companhia de Celina, artesã que produz bolsas de pano bordadas e que leva na alma a dor de uma grande perda. No Japão, Celina e Haruki, cada qual de sua maneira, seguem os passos do escritor que imortalizou a forma poética do haicai.

Rakushisha, a Cabana dos Caquis Caídos, pertence a Kyorai, discípulo de Bashô. A primeira vez que o leitor entra em contato com o lugar é para conhecer sua lenda:

Diz a lenda que Kyorai tinha cerca de quarenta pés de caqui crescendo no jardim de sua cabana em Saga, subúrbio de Kyoto. Tinha acertado a venda de frutos, certo outono em que as árvores estavam carregadas, mas na véspera do dia em que deveria entregá-los uma forte tempestade caiu, à noite. Não sobrou um único caqui. Desse dia em diante passou a chamar sua casa de Rakushisha, a Cabana dos Caquis Caídos. (LISBOA, 2007, p. 24) 
Bashô viaja até o local para escrever:

\begin{abstract}
Quanto a min, que planejo ficar por um certo tempo, deram-me um quarto num ângulo da cabana, [...] prepararam ali uma mesa de trabalho, uma estante de livros [...]. Roupas de cama, bem como diversas iguarias, foram trazidas de Kyoto, e nada me falta. Esqueço minha miséria e aprecio plenamente o bemestar sossegado. (LISBOA, 2007, p. 34)
\end{abstract}

Durante sua vida errante, Bashô viaja três vezes até a Rakushisha. Da mesma forma, sua própria moradia abandonada, a Cabana da Bananeira (Bashô-an), é visitada por amigos e discípulos.

Lugar de idas e vindas, incessantemente descritas por Bashô em seu diário ${ }^{1}$, Rakushisha é uma heterotopia, tal como definida por Foucault. A existência de lugares que abrigam escritores e intelectuais atravessa épocas e culturas, formando uma rede paratópica, se tomarmos de empréstimo o termo forjado pelo linguista francês Dominique Maingueneau. Em seu livro O contexto da obra literária: enunciação, escritor, sociedade (1995), Maingueneau, ao desenvolver sua teoria sobre a situação paratópica do escritor, cita, entre outros, o exemplo do que intitula a "paratopia do jansenismo". ${ }^{2} \mathrm{~A}$ abadia de Port-Royal, foco do pensamento jansenista na França setecentista, tornou-se centro de resistência ao poder real, atraindo escritores e pensadores como Blaise Pascal e Jean Racine. De acordo com as características estabelecidas por Foucault, poderíamos mesmo qualificar a abadia de Port-Royal como uma heterotopia de desvio, se considerarmos sua função no contexto específico da época mencionada.

Atualmente, as ruínas da abadia de Port-Royal abrigam o Musée National de PortRoyal des Champs. Também desempenhando função turística, a Hakushisha, nas proximidades do templo Tenryuji e seus jardins, pode ser visitada. Se as mesmas heterotopias tiveram suas funções modificadas no decorrer do tempo, o museu exemplifica a heterocronia foucaultiana, assim como o jardim, especialmente o oriental, ilustra o fato de ter a heterotopia "o poder de justapor em um só lugar real vários

\footnotetext{
1 "Bonchô chega de Kyoto. Kyoria retorna a Kyoto" (LISBOA, 2007, p. 48), "A monja Ukô chega para ver o festival do norte de Saga, Kyorai vem de Kyoto [...]" (LISBOA, 2007, p. 55), "Quando a noite se aproxima, Kyorai volta para Kyoto" (LISBOA, 2007, p. 62), "Senna retorna a Ôtsu. Fumikuni e Jôsô vêm nos visitar" (LISBOA, 2007, p. 101), “Otokuni vem me ver e fala de Musashi-no-kuni em Edo" (LISBOA, 2007, p. 103).

2 "A situação paratópica do escritor leva-o a identificar-se com todos aqueles que parecem escapar às linhas de divisão da sociedade: boêmios, mas também judeus, mulheres, palhaços, aventureiros, índios da América..., de acordo com as circunstâncias. Basta que na sociedade crie uma estrutura paratópica para que a criação literária seja atraída para a sua órbita" (MAINGUENEAU, 1995, p. 36).
} 
espaços, vários posicionamentos que são em si próprios incompatíveis" (Foucault, 2006, p. 418). A descrição do atual jardim da Rakushisha aparece no romance homônimo:

No horizonte, as montanhas perfiladas. No jardim, um gorinto, monumento de cinco pedras empilhadas representando a terra, a água, o fogo, o vento e o céu, homenageia todos os poetas de haicai do passado, do presente e do futuro. Mosquitos esvoaçam. 0 céu se fecha gentilmente. (LISBOA, 2007, 122)

\section{Não-lugares: identidade e anonimato}

A conceituação de heterotopia estabelecida por Michel Foucault relaciona-se com a noção de não-lugar tal como proposta por Marc Augé, em Não-lugares: introdução a uma antropologia da supermodernidade (1994). Antes de analisar a forte presença dos não-lugares no romance Rakushisha, de Adriana Lisboa, é preciso, entretanto, estabelecer algumas precisões léxicas. Em sua obra, Augé prefere o uso da palavra supermodernidade ao termo corrente pós-modernidade, por entender que a sua opção abarca uma ideia de continuidade. Em entrevista concedida ao jornal argentino Página/12, em 2007, o etnólogo francês argumenta: “A palavra pós-modernidade me parece mais descritiva que analítica [...]. É preciso pensar a cultura, a diversidade, a identidade, sempre em movimento, nunca de maneira fixa."3

Outra distinção feita por Augé é entre as conceituações de 'espaço' e de 'lugar'. Citando as referências de Michel de Certeau e de Merleau-Ponty, Marc Augé explicita que emprega o termo 'lugar' não por oposição ao termo 'espaço', como o faz de Certeau, mas como "o lugar do sentido inscrito e simbolizado, o lugar antropológico" (AUGÉ, 1994, p. 76). Paralelamente, para Augé, “o termo 'espaço', em si mesmo, é mais abstrato do que o de 'lugar', por cujo emprego referimo-nos, pelo menos, a um acontecimento (que ocorreu), a um mito (lugar-dito) ou a uma história (lugar histórico)” (1994, p. 77).

Assim, ao que chama de não-lugar, Augé vai opor o lugar antropológico, que se pretende identitário, relacional e histórico: "Se um lugar pode se definir como identitário, relacional e histórico, um espaço que não pode se definir nem como identitário, nem como relacional, nem como histórico definirá um não-lugar" (AUGÉ, 1994, p. 73). Augé propõe, dessa forma, que a supermodernidade é produtora de não-

\footnotetext{
${ }^{3}$ Entrevista dada ao jornal argentino Página/12, em 11 de abril de 2007. Cf. BINDE, João Luis. “Não-Lugares - Marc Augé". Revista Antropos - vol. 2, ano 1, maio 2008. Disponível em http://revista.antropos.com.br/downloads/Resenha\%201\%20-020N\%E3o-lugares\%20-20Marc\%20Aug\%E9\%20\%20J0\%E30\%20Luis\%20Binde.pdf. Acesso em 8 de janeiro de 2014.
} 
lugares. Ao falarmos de não-lugares, estamos nos referindo aos "espaços públicos de rápida circulação, como aeroportos, rodoviárias, estações de metrô" (AUGÉ, 1994, p. 73), assim como aos meios de transporte, mas também a grandes cadeiras de hotéis e supermercados. São "espaços de ninguém”, não geradores de identidade.

É justamente essa relação entre identidade e anonimato oferecida pelos nãolugares que vai nos interessar. Para analisar a aplicação da teoria de Marc Augé na ficção de Adriana Lisboa focaremos em especial a protagonista Celina. A hipótese que defendemos é que a reconstrução identitária da personagem se produz, no decorrer do romance, através da reconquista do anonimato que caracteriza o ocupante do não-lugar. Por não poder fornecer sua identidade, Celina perde igualmente o direito ao anonimato. Se, como sentencia Marc Augé, "o espaço do não-lugar não cria nem identidade singular nem relação, mas sim solidão e similitude" (1994, p. 95), é esta similitude (e solidão) que busca a personagem, para que, em itinerário de sentido aparentemente inverso (do século XXI ao século XVII, seguindo os passos de Bashô), a individualização, ainda que relativa, possa compor-se.

Celina, artesã que fabrica bolsas de pano bordadas para sobreviver, vê Haruki no metrô, quando o descendente de japoneses folheia o Diário de Saga, de Matsuo Bashô, cuja primeira edição brasileira ele ilustrará. "Uma mulher mais céu que carne, uma tristeza etérea, que numa tarde chuvosa o abordou no metrô de Botafogo, querendo saber sobre aquele livro estranho que ele levava nas mãos. Era japonês ou chinês?", lemos na apresentação de Rakushisha. Estranhos um ao outro, Celina e Haruki vão para o Japão. No país de Bashô, seguindo os rastros do poeta setecentista, Haruki vai de encontro a suas origens, enquanto Celina vai de encontro a si mesma. A "tristeza etérea" da personagem esconde a perda da filha Alice, em um acidente de carro, quando a menina tinha sete anos, e a consequente separação do marido (e do mundo).

Ao efetuarmos a leitura espacial de Rakushisha, tal como nos propomos no presente trabalho, observamos, inicialmente, que os encontros de Celina e Haruki ocorrem quase que exclusivamente em não-lugares: metrô, avião, internet. No Japão, longe de Haruki, quando o ilustrador viaja a Tóquio e a artesã permanece sozinha no apartamento do centro de pesquisas em Kyoto, os espaços de circulação da protagonista continuam sendo exemplares: supermercado, metrô, museu, ruas, estações de trem, 
ônibus, lojas. O lugar (antropológico) de Celina é o seu corpo. Em metonímia, os seus pés:

Foi preciso reaprender a andar. Um dia Celina se deu conta de que o que mais lhe importava em seu corpo eram os pés. [...] Sua alma pisava o chão e morava no espaço de dois complexos anatômicos, um par de tornozelos, calcanhares, tarsos, metatarsos e duas dezenas de dedos. Acotovelava-se duas vezes 26 ossos. (LISBOA, 2007, p. 20)

\title{
3 Um pé depois do outro
}

Retrocedendo ao incipit do romance, encontramos imediatamente elementos que sustentam nossa leitura:

\begin{abstract}
Para andar, basta colocar um pé depois do outro. Um pé depois do outro. Não é complicado. Não é difícil. Dá para ter em mente pequenas metas: primeiro só a esquina. Aquele sinal com a faixa de pedestres e o homem esperando para atravessar com guarda-chuva transparente e um cachorro de capa amarela. (LISBOA, 2007, p. 9)
\end{abstract}

Reaprender a andar é, antes de tudo, renascer. E nascer é, tanto para Michel de Certeau quanto para Marc Augé, um verbo espacial.

Interessado na maneira como habitamos os espaços, de Certeau, em A Invenção do Cotidiano (2000), vê o nascimento como estrutura espacial original. Para o historiador francês, o nascimento, analisado como passagem, é "uma experiência decisiva e originária, a diferenciação que ocorre quando a criança percebe ser outro corpo que o da mãe. Aí se inaugura a possibilidade do espaço e de uma localização (um "não tudo") do sujeito" (DE CERTEAU, 2000, p. 190). Continuando seu raciocínio, de Certeau, que dialoga com Freud, qualifica a infância como momento de passagem para o "eu”, que me diferencia do outro: “[...] Praticar o espaço é portanto repetir a experiência jubilatória e silenciosa da infância. É, no lugar, ser outro e passar ao outro"4 (DE CERTEAU, 2000, p. 191). Assim, a viagem, igualmente passagem, poderia ser interpretada como a possibilidade de (re)início de caminhada que fará com que a personagem Celina possa se olhar no espelho e se reconhecer 'um'. Se o ato de nascer pode equivaler a caminhar, ou a escrever, não inocentemente o romance Rakushisha,

\footnotetext{
4 Itálicos do autor.
} 
como já vimos, tem início em "Para andar, basta colocar um pé depois do outro. Um pé depois do outro" (LISBOA, 2007, p.9).

Distante da psicanálise, ao discorrer sobre os lugares antropológicos Marc Augé sentencia que "nascer é nascer num lugar, ser designado a residência. Nesse sentido, o lugar de nascimento é constitutivo da identidade individual [...]" (AUGÉ, 1994, p. 52). Sob essa ótica, a personagem Celina está longe de seu lugar de nascimento ("do outro lado do planeta"), não compartilhando, assim, com os demais, a mesma inscrição no solo. Dessa forma, não podemos ler o Japão como um lugar identitário, relacional ou histórico para Celina, em outras palavras, como um lugar antropológico, tal como poderia sê-lo para Haruki. Se o Japão não é o lugar antropológico em que Celina nasce, seu possível renascimento neste lugar só é passível de interpretação se o mesmo for considerado como um não-lugar, segundo nossa sugestão inicial.

A Kyoto que nos é apresentada por Celina não se distingue de qualquer outra cidade de seu porte. Para a protagonista de Adriana Lisboa, Kyoto pertence ao plano dos lugares de passagem, provisórios e efêmeros, aproximando-se, mesmo em se tratando de uma cidade, dos não-lugares augenianos. Celina não pertence a Kyoto - "Não pertenço a este lugar" (LISBOA, 2007, p. 9) - e não pretende significar os códigos nipônicos, encontrar saída para o que "é, e vai continuar sendo, tão labiríntico" (LISBOA, 2007, p. 11): “Como é que as coisas convivem aqui eu ainda não sei, eu talvez nem venha a saber, já vi moças de quimono comprando produtos Hello Kitty, não acredito que eu tenha a balança para isso, a régua graduada de maneira correta. Não sei se tenho a capacidade necessária de assombro" (LISBOA, 2007, p. 11).

Em sua postura de observadora passiva, a personagem se assemelha ao estrangeiro supermoderno, tal como descrito por Augé, que "só consegue se encontrar no anonimato das auto-estradas, dos postos de gasolina, das lojas de departamento ou das cadeias de hotéis" (AUGÉ, 1994, p. 98). Não por acaso, Celina percorre os nãolugares de Kyoto e as familiaridades das quais a personagem se cerca são tão genéricas, para tomar de empréstimo o termo cunhado pelo arquiteto neerlandês Rem Koolhaas, quanto suas (p)referências espaciais: 
A estação de Kyoto era um lugar de que Celina gostava. 0 movimento intenso não a intimidava. Tinha lido ser uma das maiores construções do Japão. Gostava daquela escadaria com quase duas dezenas de degraus. Da fachada futurista, com suas faces de vidro irregulares. Dos vários andares de comércio, cinemas, teatro, a loja de departamentos Isetan, e tudo disposto de um jeito meio inexplicavelmente orgânico inclusive pelo subsolo. (LISBOA, 2007, p. 50)

Confortável em seu estrangeirismo, a protagonista de Rakushisha confessa gostar dessa "familiaridade da estranheza", de se sentir "alguém que não pertence, que não entende, que não fala. De ocupar um lugar que parece não existir" (LISBOA, 2007, p. 89). Ao definir que o não-lugar cria identidades provisórias de seus usuários, Marc Augé aponta para a possível sensação de liberação provocada pelo anonimato. Assim, livre das cargas do cotidiano, Celina tem a oportunidade, em Kyoto, de, como sentencia Augé, saborear por um tempo "as alegrias passivas da desertificação", para cumprir a “experiência simultânea do presente perpétuo e do encontro de si” (AUGÉ, 1994, p. 96).

Em sua "bolha ocidental de quase-incomunicabilidade", Celina não está "em casa" nem "retoricamente à vontade". Em múltiplos sentidos, a personagem está longe de seu "país retórico", tal como definido por Vincent Descombes e citado por Marc Augé. ${ }^{5}$ Definição que encontra eco na prosa de Adriana Lisboa: “Como seria possível que se sentisse em casa ali, se não entendia nem mesmo as inscrições nas placas ao seu redor? Se não tirava sentido das palavras ditas ao seu redor?" (LISBOA, 2007, p. 38).

Mesmo assim, em aparente paradoxo, Celina se sente em casa: "Mas era uma casa. Era uma casa segura. Não havia o que temer em Kyoto, na solidão que tinha em Kyoto, aquela afável solidão acompanhada" (LISBOA, 2007, p. 38). 0 aparente paradoxo converge para a conclusão de Augé, quando o etnólogo sentencia que "no mundo da supermodernidade, sempre se está e nunca se está 'em casa'”, uma vez que não há “mundos totalmente estrangeiros" (AUGÉ, 1994, p. 100).

Podemos ir além e arriscar mesmo afirmar que qualquer paradoxo se desfaz quando compreendemos a amálgama como característica da contemporaneidade, convertida em supermodernidade por Augé. Ele mesmo confirma a interpenetração

\footnotetext{
5 “Onde o personagem está em casa? A questão diz respeito menos ao território geográfico do que ao território retórico [...]. 0 personagem está em casa quando fica à vontade na retórica das pessoas com as quais compartilha a vida. 0 sinal de que se está em casa é que se consegue se fazer entender sem muito problema, e ao mesmo tempo se consegue entrar na razão de seus interlocutores, sem precisar de longas explicações. 0 país retórico de um personagem para onde seus interlocutores não compreendem mais as razões que ele dá de seus fatos e gestos, nem as queixas que ele formula ou as admirações que manifesta." (DESCOMBES, Vincent. Proust, philosophie du roman. Editions de Minuit, 1987, 179, apud AUGÉ, Marc, 1994, p. 99).
} 
entre "lugares" e "não-lugares", gerando a impossibilidade de configurações puras, essenciais. No apartamento de Kyoto, abrigo temporário pertencente ao centro de pesquisas, e que, assim sendo, se aproxima funcionalmente da cabana heterotópica de Bashô, Celina observa esta superposição:

\begin{abstract}
Presas com um ímã na porta da geladeira estão as instruções para a coleta seletiva de lixo. Sobre a pia, os pepinos e os tomates, as maçãs, os cogumelos e o alho. As pessoas que moraram antes neste apartamento deixaram coisas, e o pequeno espaço é uma pequena confluência do mundo também, um palimpsesto de gente que passou, mas quis firmar o atestado da sua passagem numa ou noutra pequena gentileza. (LISBOA, 2007, p. 33)
\end{abstract}

Gentileza que pode ser grafada. Como a que faz Bashô em relação à personagemleitora Celina, possibilitando que ela mesma se combine em personagem-autora. Leitora do diário escrito por Bashô, Celina começa a escrever o seu próprio diário. E é através da escritura, a nosso ver, que a personagem reconquista o direito ao anonimato, recuperando sua similitude.

\title{
4 Um lugar sem lugar
}

A escritura do diário é o paroxismo do solitário confronto com a imagem de si mesmo, do anonimato obtido através do "rosto e voz da solidão". Ao escrever seu diário, Celina estabelece a relação contratual que caracteriza o uso do não-lugar, provando, assim, a sua inocência. Através do registro de suas experiências, Celina, que entrou no Japão invisível - "Pode-se dizer que vim escondida dentro da bagagem de outra pessoa. É como se eu tivesse entrado clandestina, apesar do visto no meu passaporte" (LISBOA, 2007, p. 9) -, ganha status de passageira, "assina o contrato" com os demais ocupantes do não-lugar. Antes de seu encontro com Bashô, Celina nunca havia pensado em escrever um diário: "Talvez esteja fazendo isso agora só porque não resisti ao papel fabricado no Japão" (LISBOA, 2007, p. 23).

Sem abordar detalhadamente a questão do diário enquanto gênero literário, o que ampliaria e desviaria de rumo a presente discussão, é senso comum que, a princípio, o diário não pretende alcançar uma dimensão artística. Sem destinar-se à publicação, ou sequer à leitura, o objetivo daquele que mantém um diário é, através do relato cotidiano de suas experiências, melhor compreender a si mesmo. 0 papel (ou a tela do 
computador) serve, então, como espaço de confidência e como guardião de memórias. Obviamente, esta função original pode mudar e ganhar valor literário, em especial se o diário é mantido por um escritor, como é o caso do Diário de Saga. Ao contemplar os diários da personagem fictícia Celina e do poeta Matsuo Bashô, o romance de Adriana Lisboa se prestaria convenientemente a esta discussão.

É, entretanto, a dimensão essencial do diário, ou seja, a escrita privada, o que nos interessa particularmente no que diz respeito à trajetória da personagem Celina. Ao analisar as escritas em primeira pessoa, no texto intitulado "A Ilusão Autobiográfica" (1992), Wander Melo Miranda, citando o crítico literário suíço Jean Rousset, chama a atenção para a perspectiva de autodesvelamento contida no diário. Diz Melo Miranda: “Na 'autodestinação', redator e leitor são idênticos, escrever e reler-se são operações complementares: a releitura oferece ocasião para novas reflexões do diarista sobre si mesmo [...]" (1992, p. 35).

Podemos afirmar, ainda, que, por seu caráter presenteísta, que aproxima fato e escritura, o diário possibilita a construção de si a partir da própria narração, independente de toda a discussão sobre a ficcionalidade que poderia estar contida nesta autoescritura. Diário-espelho. A imagem de si desenhada nas páginas do diário se aproxima, neste ponto, da criança que, ao olhar-se no espelho, se reconhece um (nasce), "mas não é senão o outro (isto, uma imagem com a qual se identifica)", como analisa de Certeau (2000, p. 191).

Dupla experiência que é também citada por Foucault, quando o filósofo posiciona o espelho como "um lugar sem lugar", misto de utopia e heterotopia, como já mencionamos anteriormente. É a bela imagem criada por Foucault que pedimos de empréstimo para definir o (re)nascimento de Celina através de sua escritura especular:

No espelho, eu me vejo lá onde não estou, em um espaço irreal que se abre virtualmente atrás da superfície, eu estou lá longe, lá onde não estou, uma espécie de sombra que me dá a mim mesmo minha própria visibilidade, que me permite me olhar lá onde estou ausente: utopia do espelho. [...] é a partir do espelho que me descubro ausente no lugar em que estou porque eu me vejo lá longe. (FOUCAULT, 2006, p. 415)

"Lá longe" é o espaço que Celina precisa percorrer para que sua viagem esteja dotada de função. Bildung. "Lá longe" é o espaço medido em distância ("do outro lado do planeta"), mas é também o espaço medido em tempo, os 300 anos que separam a 
protagonista do poeta japonês. Tempo e espaço, utopia e heterotopia, "lá longe" é, enfim, a confluência entre lugar e não-lugar. Amálgama. Ritornelo.

\section{Poesia do silêncio}

Para concluir a viagem pelas águas ficcionais de Rakushisha, é fundamental desviar o olhar e buscar a segunda imagem: o haicai. Em sua construção narrativa bidimensional, Adriana Lisboa insere não apenas fragmentos do Diário de Saga, mas também haicais escritos por Matsuo Bashô. 0 artifício, sob a ótica da leitura espacial a que nos propomos, não é irrelevante, uma vez que o haicai, forma poética revestida de tradição, pode ser interpretado como expressão retórica desta supermodernidade em que urgência rima com transitoriedade.

As características básicas do haicai são a simplicidade, a brevidade e a cesura. Em geral, o poema é construído sob duas imagens: a primeira que o situa no espaço e no tempo e a segunda que apresenta um elemento inesperado, surpreendendo o leitor. Esta conceituação ocidental, entretanto, de um Ocidente que "umecta todas as coisas com sentido" (BARTHES, 2007, p. 92), precisa se inventariada com o mesmo cuidado que um poeta nipônico trabalharia suas palavras. Diz Roland Barthes, em seu O Império dos Signos (2007):

\footnotetext{
Decifradoras, formalizantes ou tautológicas, as vias de interpretação, destinadas entre nós a penetrar o sentido, isto é, a fazê-lo entrar por arrombamento - e não a sacudi-lo, a fazê-lo cair [...], só podem, pois, perder o haicai; pois o trabalho de leitura a ele ligado consiste em suspender a linguagem, não em provocá-la [...]. (BARTHES, 2007, 95)
}

A partir de suas características básicas, seria bastante clara, como dissemos anteriormente, a aproximação entre o haicai e a supermodernidade da urgência, instantaneidade e efemeridade. Entretanto, seguindo o raciocínio de Barthes, para espelhá-lo no de Marc Augé, que nos trouxe até aqui, é muito mais pelo que silencia, pelo que cria de anonimato, que o haicai poderia ser tido como uma expressão literária supermoderna, como um não-lugar: 
Ao mesmo tempo que é inteligível, o haicai não quer dizer nada, e é por essa dupla condição que parece ofertado ao sentido de modo particularmente disponível, prestativo, como um hospedeiro polido que nos permite instalarmonos à vontade em sua casa, com nossas manias, nosso valores, nossos símbolos [...]. (BARTHES, 2007, p. 91)

Em sua forma "breve e vazia", "o haicai nunca descreve: sua arte é contradescritiva", na mesma medida em que o espaço do não-lugar, na urgência do momento presente, "não concede lugar à história" (AUGÉ, 1994, p. 95). A isenção de sentido do haicai faz com que ele, a exemplo do não-lugar, não seja, a nossos olhos, "nem excêntrico nem familiar", instalando o que Barthes denomina de "a visão sem comentário".

Contrapondo o haicai à literatura ocidental, Barthes reveste esta última com as mesmas características do lugar antropológico augeniano. Assim, no haicai desaparecem "as duas funções fundamentais de nossa escrita clássica (milenar): de um lado, a descrição [...], e, do outro lado, a definição [...]" (BARTHES, 2007, p. 111). Essencialmente prescritivo, proibitivo ou informativo, o texto do não-lugar supermoderno se aproxima deste haicai que "emagrece até a pura e única designação" (BARTHES, 2007, p. 112). Se no haicai, o sentido "é apenas um flash, um arranhão de luz", a história, no não-lugar, é transformada em texto alusivo.

Assim sendo, podemos concluir que da mesma forma que a plenitude do nãolugar é o anonimato, a plenitude do haicai é o silêncio. Semelhança que o narrador de Adriana Lisboa parece não ignorar:

\footnotetext{
É verdade que o mundo mais inexiste do que existe. 0 mundo é menos. Ainda que esteja povoado por feitos, fatos, palavras, ruídos, imagens, construções, guarda-chuvas, uma livraria como esta em que entro e vou galgando escadas rolantes para chegar ao último andar - quantos são? Dez, contei direito? mesmo sem entender o que dizem as capas dos livros e das revistas, estes dez andares de livros, digamos que sejam dez, podem ruir a qualquer momento debaixo dos meus pés, porque há neles muito mais espaço, muito mais silêncio. Muito mais não-palavras do que palavras. (LISBOA, 2007, p. 64)
}

No corpus do presente ensaio, reproduzimos a concepção do etnólogo francês Marc Augé de que a cultura deve ser pensada em situação de movimento e compreendida em correlação histórica. Para tanto, é absolutamente necessário destacar, enquanto conclusão analítica, o papel do texto literário em suas conexões com o mundo real e com a vida contemporânea. No ensaio A literatura em perigo, Tzvetan Todorov 
tece um apelo - quase dramático, por vezes - pelo risco de a literatura não mais participar da formação cultural do cidadão. 0 que o ensaísta franco-búlgaro ataca é a perda da capacidade do texto literário, em 25 séculos de história, de "falar do e para o mundo real contemporâneo" (TODOROV, 2009, p. 10).

Objetivando delimitar a importância das abordagens estruturalista e formalista das décadas precedentes, pelas quais se guiou, Todorov admite que elas devem ser compreendidas como andaimes destinados ao desaparecimento após a construção do prédio. Assim, o teórico critica a abordagem interna estrita do texto literário, se afastada da concepção de que "as obras existem sempre dentro e em diálogo com um contexto" (TODOROV, 2009, p. 23). Ao expressar semelhante caráter da obra literária, Tzvetan Todorov alinha seu texto ao pensamento dos teóricos que nos acompanharam na elaboração das linhas deste ensaio.

Para tanto, assim como Celina fabricava suas bolsas de pano bordadas (metáfora da própria literatura), costuramos retalhos da formação identitária da personagem tema que, paralelamente ao da construção identitária autoral vem despertando interesse dos teóricos literários - através da concepção teórica augeniana dos nãolugares e seus componentes de anonimato. Nossa viagem incluiu, ainda, a equivalência dos atos de nascer, caminhar e escrever, para destacar o fio tênue (como a teia da aranha, na metáfora criada por Adriana Lisboa) que conduziu a personagem-leitora Celina à personagem-autora Celina.

A obra literária. Essa é a dimensão visual do que podemos comparar ao haicai, enquanto transcrição em "matéria visível" de realidades externas e internas. Matéria visível que, por sua vez, será desdobrada em novas matérias visíveis, revelando insuspeitas profundidades. Porque é esse o grande desafio e prazer do comparativismo: aproximar realidades distantes, para que salte a fagulha, para que se crie a imagem (fazemos referência, aqui, aos conceitos Donald Keene e de Pierre Reverdy sobre o haicai e a imagem poética). Imagem que, por sua vez, simbolizará a transgressão da própria comparação, que, através da teoria, deixa de ser figura de estilo para transformar-se, enfim, em figura de pensamento. 


\section{Referências}

AUGÉ, Marc. Não-lugares: introdução a uma antropologia da supermodernidade. Tradução de Maria Lúcia Pereira. 7ạ ed. São Paulo: Papirus, 1994.

BARTHES, Roland. O Império dos Signos. Tradução de Leyla Perrone-Moisés. São Paulo: Martins Fontes, 2007.

CAMPOS, Haroldo de. A Arte no horizonte do provável. São Paulo: Perspectiva, coleção Debates, n. 16, 1977.

DE CERTEAU, Michel. A Invenção do Cotidiano. 1. Artes de fazer. Tradução de Ephraim Ferreira Alves. 5aㅡ ed. Petrópolis: Editora Vozes, 2000.

FOUCAULT, Michel. "Outros Espaços". In: Ditos e Escritos III: Estética: Literatura e Pintura, Música e Cinema. Tradução de Manoel Barros da Motta. São Paulo: Forense, 2006.

LISBOA, Adriana. Rakushisha. Rio de Janeiro: Editora Rocco, 2007.

MAINGUENEAU, Dominique. O contexto da obra literária: enunciação, escritor, sociedade. Tradução de Marina Appenzeller. São Paulo: Martins Fontes, 1995.

MIRANDA, Wander Melo. Corpos escritos. São Paulo: Edusp; Belo Horizonte: Ed. UFMG, 1992.

TODOROV, Tzvetan. A literatura em perigo. Tradução de Caio Meira. Rio de Janeiro: DIFEL, 2009.

Recebido em março de 2014.

Aceito em junho de 2014. 